\title{
Convert Development Modes of University and Optimize Practice Teaching Environment
}

\author{
Canwei Wang \\ Shandong Management University, Jinan Shandong, 250300, China
}

\begin{abstract}
Keywords: Higher education, Connotative development, Application-oriented institutions, Practical teaching.
\end{abstract}

\begin{abstract}
The higher education in China has already entered the stage of mass education, and it is an inevitable trend for universities to convert traditional extended development mode to connotative development mode. The core task of connotative development is to enhance the quality of education but without increasing investment in education or with a small increase. Application-oriented institutions, as an important growth pole of current higher education, compared to research institutions, put more emphasis on the cultivation of talent application skills. Therefore, on condition of strongly advocating higher education connotative development, for application-oriented institutions, it has important practical significance to make efforts to improve the practice teaching environment, and improve the quality of practice teaching. Taking Shandong Institute of Management for example, this paper in-depth analyzes the shortcomings of the existing higher education models, proposes a set of scientific and reasonable teaching system based on years of practical teaching experience, and attempts to explore the open sharing laboratory management model and school-enterprise deep cooperation model, in order to benefit the connotative development of university, as well as provide a theoretical basis for laboratory construction of similar institutions .
\end{abstract}

\section{Introduction}

Our substantial reduction in enrollment of higher education began in 2006, which indicates that our higher education has begun to enter the mass education stage proposed by the famous American educator, Professor Martin Trow, and until now, higher education extended development is also successfully completed, accomplishing the historical mission of solving "difficult to be enrolled by colleges" problem. Along with the emergence of "985", "211" and a number of domestic famous universities, China has become one of countries with strong higher education in the world. But with the rapid expansion of students in colleges and universities, our higher education is not consistent with international mass education stage, for example, the teacher-student ratio is insufficient, resource for per student is inadequate, experimental equipment is not complete, and blind extensive construction causes the debt pressure and so on. These contradictions are more obvious in newly-built application-oriented undergraduate colleges and polytechnic colleges. In 2013, 41 colleges and universities accepted the undergraduate teaching conformity assessment by Ministry of Education, "Construction and Use of Laboratory Internship Sites” . Among test items, over 17.1\% cannot meet the standards, and 12\% tudent-teacher ratio is non-compliant [].To regulate these contradictions, higher education connotative development model has become the inevitable trend, significantly improving the quality of education with no increase or slight increase in investment in education []. There is lot of literature on higher education connotative development, but because connotative development of higher education is involved with many factors, and government departments and higher education researchers do not have an entirely unified viewpoint on connotative development. Therefore, it will be a long and innovative exploration job to really implement connotative 
development of higher education. But enhancing the quality of higher education has become the common understanding of all parties on the core mission of higher education connotative development.

Compared with research-oriented universities, teaching target of application-oriented undergraduate colleges is to develop high-quality skilled personnel in line with the social needs. Therefore, to promote connotative development, application-oriented universities should boost students' practical skills. Training of application skills more relies on practice teaching, therefore, practice teaching is essential for connotative development of application-oriented undergraduate colleges. In recent years, many application-oriented undergraduate colleges have gradually realized the importance of practical teaching to the development of schools, and more and more attention tend to be put on practice teaching in the teaching plan. The Ministry of Education issued and printed in 2015 "on guiding part local general undergraduate colleges on transition of application-orientation” , which clearly proposed to innovate skilled personnel training, strengthen the experiment, training, internships and establish the personnel training process aimed to improve the practical ability. This paper is intended to take Shandong Institute of Management for example, explore how to optimize higher education practice teaching environment, and provide high-quality soil for the higher education, especially the connotative development of application-oriented undergraduate colleges education.

The paper is organized as follows. First, in-depth analyze the drawbacks of current education model in the practice teaching; second, partly combine research results of Shandong Provincial Education Planning Research Group to propose a relatively reasonable time teaching system; third, based on this system, explore an open and shared experiment management model; forth, to broaden employment outlet, continue to explore school-enterprise cooperation relationship; and finally summarize and discuss the content of this paper.

\section{The drawbacks of the current higher education model}

While the research on the connotative development of higher education connotation is for nearly 20 years, but after rapid expansion of the past extended development, it will still take a long time of exploration for colleges to really realize the core tasks of connotative development. In the transition period, current college education model has the following major contradictions.

Institutions, teachers, students, laboratory management mode (lack personalized service)

1). Practical teaching disconnect career demands

Currently, in the course plan of most colleges, the class-time ratio of theoretical courses and practical lessons is basically up to 1: 1 or so, to meet the requirements for the class time of application-oriented undergraduate colleges, but in terms of practice teaching content setting, too much attention is paid to theoretical courses, namely there are too many verification experiments, but few innovative exploratory experiments.

2). Experimental equipment is insufficient

3). Experimental teaching management is lacking

4). Personalized teaching service is in vacancy

5). Innovative application-oriented practice teaching is inadequate

Teaching evaluation criteria awareness to serve the community is weak

6). Students lack the motivation and interest in practice teaching

\section{Construct scientific practice teaching system}

Practice teaching system explored by Shandong Institute of Management starts with serving economic development in Shandong Province, focuses on actual working capacity and basic quality training required by first-line business, takes ways of school-business combination, theory-practice combination, teaching-production combination, and trains highly skilled personnel jobs need with characteristics of "practicality, training, and effectiveness" . After years of teaching exploration, it 
has formed a targeted, strongly practical, innovative practice teaching system. Confirm the practice teaching development principles of "adhere to connotation, highlight features, and serving the society", and the guiding thoughts of training application-oriented personnel with "thick foundation, strong practice, and high quality" to improve the students' level of operating practice and innovation.

1). Optimization of practical teaching

Practical teaching should be guided by the principle of "reinforcing the trunk by cutting off the branches", to actually serve regional economic and social development in Shandong, strengthen work and study, and closely cooperate with schools and enterprises. Put emphasis on systematization, continuity, practicality and innovation of cognitive training, curriculum test / training, graduation design, graduation practice, etc, and focus on training of vocational competence in skills courses, to ensure that students can master the core skills.

In accordance with the requirements of the relevant professional positions and professional capacity training, blend the professional standards into the curriculum standards of professional courses, in a targeted manner strengthen students' professional capacity-building and development of quality. During integration and optimization of professional curriculum content, we should pay attention to absorb new equipment, new knowledge, new technology, new standards of professional standards and network technology industry, and strengthen the capacity for sustainable development of students.

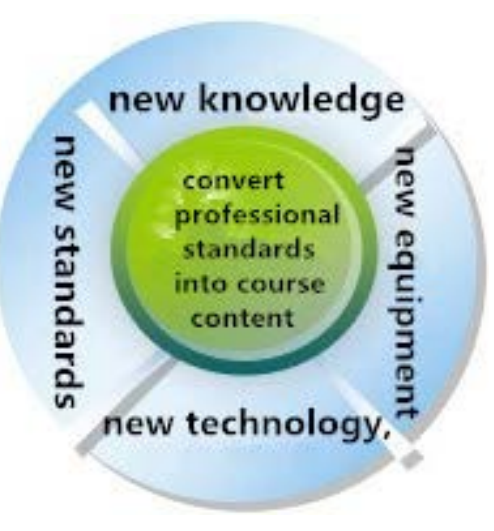

2).Hierarchical practice teaching design

The practice teaching content is designed to enable students to hierarchically complete four-level open training programs including basic training, simulation training, project training, graduation design / internship, to enable students to meet the requirements of the curriculum standards, and improve students' learning ability, operational skills, practical ability and professional capability. 


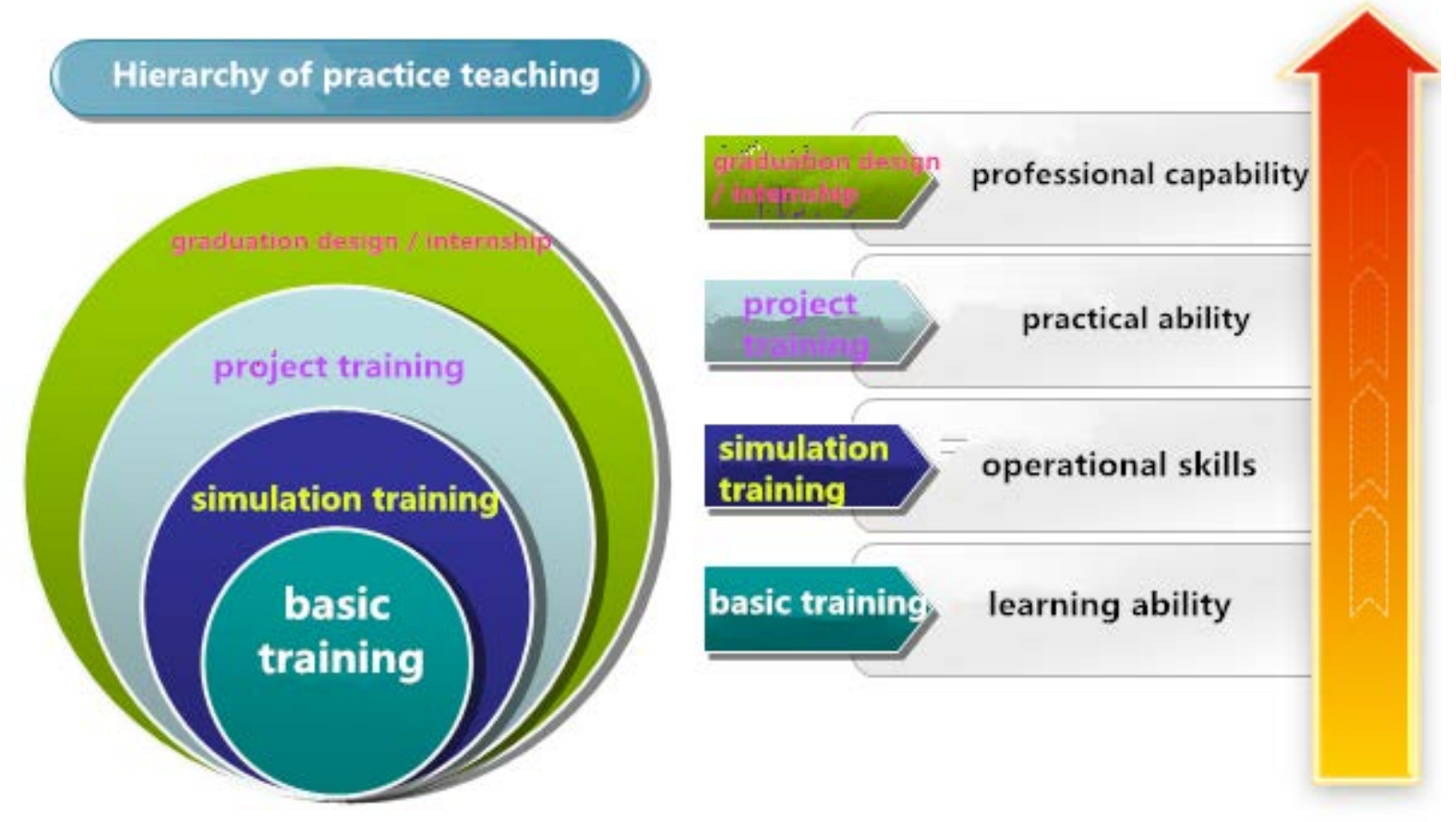

Use actual task to drive practice teaching and improve practical skills. Explore the work-study new model of "use real business projects to drive practice teaching and use projects to test teaching" to encourage students to learn in the project, to hone in actual combat, and to improve themselves in applications.

3). Pay enough attention to the guiding role of theoretical courses on practice teaching

4). Practice assessment

We examine students' practical ability as the purpose, and after the absorption of advanced assessment model for application of skills development in Germany and Australia and other countries, we change the traditional single practice examination form, and pay attention to the process assessment in practice-oriented teaching. After completing this practice course, students will achieve a consolidated result of personal skills, application and innovation, teamwork, project presentation, and their respective proportion in practical course consolidated result are as follows, 0.4: 0.2: 0.2 : 0.2 .

Personal skills: whether their understanding on the mission statement is right or not; whether the operation is standard or normative;

Application and innovation: whether the practice project includes the application background; whether it has a certain innovation;

Teamwork: cooperation, project management;

Project presentation: presentation, expression.

Blend professional standards into curriculum standards, and incorporate into new technologies in network technology industry.

While focusing on training students' basics of networking major, conduct full discussion with the domestic network technology specialists in universities and network technology technicians in companies.

\section{Explore open laboratory management system}

The laboratory construction goal we explored keeps up with the new trend of development of the industry, to build a public education and program development platform for modern network technology and information technology, explore the comprehensive skills training and innovative 
research skills training, optimize the overall quality of students, explore diversified talents training model, to achieve the integration of theories, experiments, skills training, and overall quality training. Experiments / training rooms achieve "three opens" including experiment time, experiment content and experiment objects, in the forms of "double-teacher" guidance, group discussion, and self-learning. In experiments / training rooms construction process, we adhere to the principle of "building, research, development, opening up". According to the content of students' practical projects, conduct modular expansion on the basis of the current platform. Pack students' mature innovation results, help students to convert them into finished products, promote students' outcomes to the market, and push our students to the community.

We follow the school policy of "come in and go out", actively direct contact with the enterprise, highlight the cultivation of students' professionalism while further strengthening vocational skills training, and improve the organic integration of professional standards and curriculum standards, to enable students to experience professional atmosphere or first-line workers in enterprises during school. In addition, pay attention to the effectiveness of practices. According to "promote and send" program, promote students' work with innovative value to the market. In the last semester, professional teachers take the initiative to contact with cooperative enterprises, to send students to to society through graduation internship.

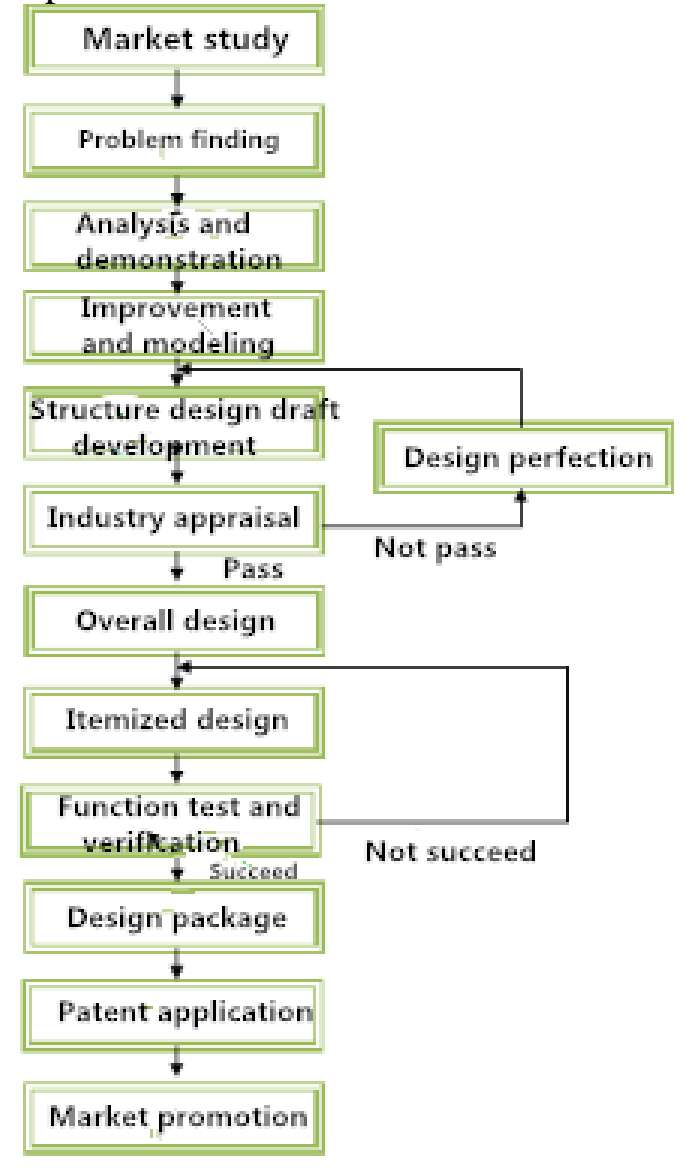

\section{Explore deep school-enterprise cooperation mode}

School-enterprise cooperation involves multiple stakeholders including government departments, schools, businesses, etc. School-enterprise cooperation modes in previous research literature include, shallow cooperation, intermediate cooperation and deep cooperation. Prior research literature focuses on the relationship between schools and businesses. We are talking about: school: Basic knowledge and overall quality training, especially the guiding role of theoretical courses related with vocational skills, aimed to have sustainable development talents with enough theoretical support and learning capacity; enterprise: professional skills and professionalism training, especially the influence of 
entire professional atmosphere including the corporate culture, mainly aimed to develop application-oriented talents who can meet job skill requirements in terms of depth, and be good at communication with others in terms of breadth; government: as direct participants, for schools and businesses, fees, enrollment forms and numbers, admissions and employment security are all constrained by relevant government departments; students: students are not only as passive objects of cultivation and also as an independent participant in the school-enterprise cooperation. For enterprises, they can ease the tension of corporate human resources; for schools, they can serve as another channel for professional research, and feedback to schools about if theoretical course setting meets the need of jobs, and disconnects with industry, which is beneficial for revising personnel training program.

\section{Summary}

How to use Evergreen College Town to found School-School Consortium to promote "entrepreneurship by masses and innovation by all"

Take full use of the Internet, and network bandwidth during leisure time of campus network.

\section{Acknowledgement}

This article is the phased result of Shandong Province Educational Science Planning Computer Teaching Special Project, "Research on Application of Cloud Computing Technology in Computer Practice Teaching", Project Number: YBJ15005.

\section{Reference}

[1] Zhong Binglin New Colleges Should Attach Great Importance to Connotative Development and Quality Construction, China Higher Education Research, 2015 (06) P68-72.

[2] China Internet Development Status Statistics, 2015.7. 